\title{
Simultaneous Electrochemical Determination of Uric Acid and Ascorbic Acid on a Glassy Carbon Electrode Modified with Cobalt(II) Tetrakisphenylporphyrin
}

\author{
Chun-Xiang LI, ${ }^{* \dagger}$ Yun-Long ZENG, ${ }^{* *}$ Ying-Ju LIU, $* *$ and Chun-Rang TANG* \\ *Chemistry and Chemical Engineering College, Hunan University of Science and Technology, \\ Xiangtan 411201, P. R. China \\ ** State Key Laboratory of Chemo/Biosensing and Chemometrics, Chemistry and Chemical Engineering College, \\ Hunan University, Changsha 410082, P. R. China
}

\begin{abstract}
A cobalt(II) tetrakisphenylporphyrin (Co(II)TPP) film modified glassy carbon electrode (Co(II)TPP-GCE) was prepared by just coating Co(II)TPP solution on the surface of the electrode. It can be used for the simultaneous determination of ascorbic acid and uric acid. The anodic peaks of AA and UA can be separated well. Owing to the strongly hydrophobic property of porphyrin, the modified electrode has good stability and long life. The linear range for UA and AA were 2.0 $\times 10^{-6}-1.0 \times 10^{-4} \mathrm{M}$ and $9.0 \times 10^{-6}-2.0 \times 10^{-3} \mathrm{M}$ with detection limits of $5.0 \times 10^{-7}$ and $5.0 \times 10^{-6} \mathrm{M}$, respectively. Furthermore, metalloporphyrins of other kinds were also used to construct modified electrodes. Their performances were inferior compared with that of the Co(II)TPP modified electrode.
\end{abstract}

(Received June 2, 2005; Accepted October 13, 2005)

\section{Introduction}

Uric acid (UA) and ascorbic acid (AA) are both present in biological fluids, such as blood and urine. Uric acid has often been associated with cardiovascular disease ${ }^{1}$ hyperuricaemia, uric acid stones, ${ }^{2}$ gout, and Lesch-Nyhan syndrome. ${ }^{3}$ It is well known that superabundant UA is the symptom of several diseases. ${ }^{1}$ Therefore, various methods have been developed to determine the content of UA, such as enzyme biochip system, ${ }^{4}$ fluorescence, ${ }^{5}$ liquid chromatography, ${ }^{6}$ and scanning electrochemical microscopy/scanning chemiluminescence microscopy. ${ }^{7}$ Ascorbic acid is a powerful water-soluble antioxidant. It plays a key role in protecting against oxidative injury and has been used clinically for the treatment and prevention of scurvy, common cold, mental illness, cancer and AIDS. ${ }^{8-11}$ Moreover, extreme AA levels can cause gastric irritation, diarrhea, and renal problems. ${ }^{9}$ Thus, the detection of AA is very important for biological research. Numerous techniques have been employed, such as capillary zone electrophoresis, ${ }^{11}$ spectrofluorometry, ${ }^{12}$ flow injection, ${ }^{13-15}$ voltammetry, ${ }^{16,17}$ fluorescence, ${ }^{18}$ and chemiluminescence. ${ }^{19}$ Recently, electrochemical sensors have attracted much attention due to their advantages of simplicity, cheapness, fast analysis along with high sensitivity and selectivity. ${ }^{20}$ It has also been used for the determinations of UA or AA. ${ }^{21,22}$ However, a major problem is, at substrate electrodes, that the anodic peak potentials for AA and UA are almost the same, ${ }^{3,23}$ which results in overlapped current responses, and makes their discrimination very difficult. Thus, the discrimination of the co-existence of $\mathrm{UA}$ and $\mathrm{AA}$ is a problem of critical importance in the field of

† To whom correspondence should be addressed.

E-mail: cxli@hnust.edu.cn biomedical chemistry. The increasing requirement for the simultaneous determination of these compounds led to the development of new techniques. ${ }^{23-25}$ Khoo et al. immobilized methylene blue in a methyltrimethoxysilane sol-gel ceramic film on a glassy carbon electrode for the simultaneous determination of AA and UA. ${ }^{24}$ Raj and coworkers fabricated a sensor based on a self-assembled monolayer of a heteroaromatic thiol for the same purpose. ${ }^{3}$

Porphyrins and metalloporphyrins exist broadly in animals and plants. Such molecules as haemachrome, chlorophyll, and cytochrome P-450, have special physiological properties. They are eligible as good sensing materials to detect different substances presented in environment because of a great number of peculiar features. ${ }^{26-28}$ Furthermore, they have also been used extensively as catalysts, semiconductors, anticancer medicine, etc. ${ }^{29,30}$ In this work, we described a different electrochemical method for the simultaneous determination of uric acid and ascorbic acid by using metalloporphyrin film modified glassy carbon electrodes. Here, cobalt(II) tetrakisphenylporphyrin (Co(II)TPP) showed better performances, including stability, sensitivity, selectivity, and usage life. The separation of the anodic peaks of AA and UA was sufficient for the determination of a mixture of AA and UA. The preparation process of modified electrodes was very simple by just spreading porphyrin solution on the surface of a glassy carbon electrode.

\section{Experimental}

\section{Reagents and apparatus}

Porphyrin and metalloporphyrins were prepared according to the literature, ${ }^{31}$ which were dissolved in $\mathrm{N}, \mathrm{N}$ dimethylformamide (DMF). Uric acid (Aldrich), ascorbic acid 


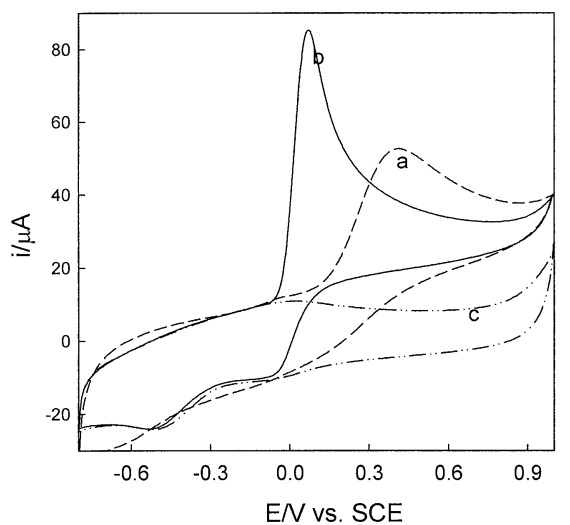

Fig. 1 Cyclic voltammograms of $4 \mathrm{mM} \mathrm{AA}$ in $0.1 \mathrm{M} \mathrm{PBS}$ (pH 6.5) at a scan rate of $100 \mathrm{mV} \mathrm{s}^{-1}$. a, bare GCE; b, Co(II)TPP-GCE; c, Co(II)TPP-GCE without AA.

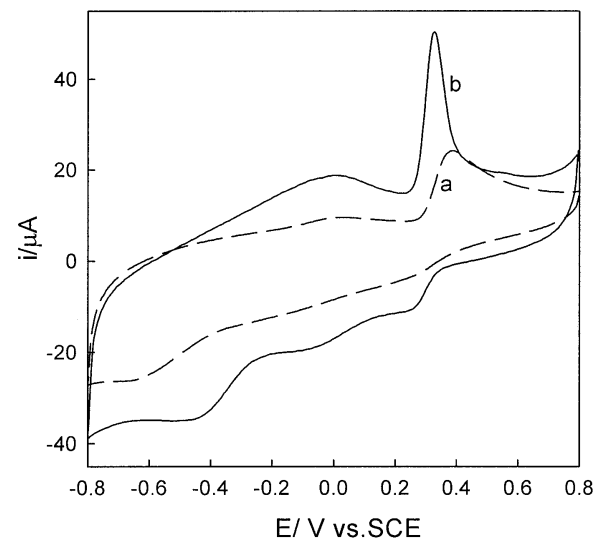

Fig. 2 Cyclic voltammograms of $0.2 \mathrm{mM}$ UA in $0.1 \mathrm{M}$ PBS (pH 6.5) at a scan rate of $100 \mathrm{mV} \mathrm{s}^{-1}$. a, bare GCE; b, Co(II)TPP-GCE.

(Aldrich), other chemicals were of analytical reagent grade. The supporting electrolyte was $0.1 \mathrm{M}$ phosphate buffer solution containing $0.1 \mathrm{M} \mathrm{KCl}$ (PBS), which was prepared with $\mathrm{NaH}_{2} \mathrm{PO}_{4} \cdot 2 \mathrm{H}_{2} \mathrm{O}$ and $\mathrm{Na}_{2} \mathrm{HPO}_{4} \cdot 2 \mathrm{H}_{2} \mathrm{O}$. Double-distilled water was used throughout.

All electrochemical experiments were performed on an electrochemical analyzer (Tianjin, China). A three-electrode system consisted of a Co(II)TPP modified glassy carbon electrode (Co(II)TPP-GCE) as working electrode, a saturated calomel electrode (SCE) as reference electrode and a platinum wire auxiliary electrode. All potentials were with respect to SCE. The assay cell was stirred with a magnetic stirrer. All electrochemical measurements were performed at room temperature.

\section{Preparation of Co(II)TPP film modified GC electrode}

The bare glassy carbon electrode (GCE, diameter $4 \mathrm{~mm}$ ) was treated by polishing on fine emery paper, and then 1.0 and 0.05 $\mu \mathrm{m}$ alumina powder until obtaining a mirror-like surface. It was next rinsed with double-distilled water thoroughly. Then, it was sonicated in 1:1 nitric acid, acetone, $\mathrm{NaOH}$, and doubly distilled water for $5 \mathrm{~min}$, respectively. After being cleaned, $2 \mu \mathrm{l}$ of $4 \mathrm{mg}$ $\mathrm{ml}^{-1} \mathrm{Co}(\mathrm{II}) \mathrm{TPP}$ solution was dropped onto the surface of the glassy carbon electrode and dried in air. Finally, the electrode was thoroughly rinsed with water and activated by cyclic potential scanning from $-1.0-1.5 \mathrm{~V}$ in $0.1 \mathrm{M}$ PBS for 5 cycles.

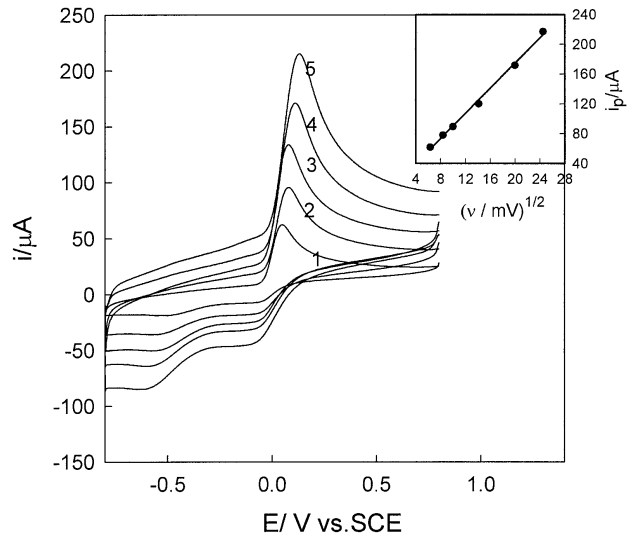

Fig. 3 Cyclic voltammograms of Co(II)TPP-GCE at different scan rates in $0.1 \mathrm{M}$ PBS (pH 6.5) containing $4 \mathrm{mM} \mathrm{AA}$. Scan rates from 1 to 5 correspond to $40,100,200,320,600 \mathrm{mV} \mathrm{s}^{-1}$, respectively. The inset shows the relationship of the scan rate versus the peak current.

\section{Results and Discussion}

\section{Electrochemical behavior of UA and AA}

Figure 1 shows the cyclic voltammograms (CVs) of AA at bare GCE and Co(II)TPP-GCE. The oxidation peak of AA was broad at the bare GCE (Fig. 1a) with an $E_{\mathrm{p}}-E_{\mathrm{p} / 2}$ of $0.25 \mathrm{~V}$. In contrast, at Co(II)TPP-GCE, the response current increased greatly and the peak potential shifted negatively from +0.4 to $+0.05 \mathrm{~V}$ with a small $E_{\mathrm{p}}-E_{\mathrm{p} / 2}$ of $0.054 \mathrm{~V}$ (Fig. 1b), which showed a strong catalytic function of Co(II)TPP to the oxidation of AA. Moreover, a voltammogram of the Co(II)TPP-GCE in PBS was also obtained (Fig. 1c). A pair of reversible anodic and cathodic waves were found at $-0.02 \mathrm{~V}$ and $-0.08 \mathrm{~V}$, which were assigned to the $\operatorname{Co}(\mathrm{II} / \mathrm{I})$ redox pair. Compared with the oxidation peak of AA, they were very weak. In addition, an irreversible cathodic peak could also be seen at about $-0.5 \mathrm{~V}$, which was ascribed to the monoelectronic reduction of porphyrin ring to the $\pi$-radical anion. ${ }^{32}$

For the UA, the voltammetric behavior was almost similar to the above (Fig. 2). An irreversible anodic wave appeared at $+0.4 \mathrm{~V}$ at bare GCE (Fig. 2a) with an $E_{\mathrm{p}}-E_{\mathrm{p} / 2}$ of $0.16 \mathrm{~V}$. However, at the Co(II)TPP-GCE, a negative shift of $0.08 \mathrm{~V}$ of the anodic wave could be found (Fig. 2b). Compared with the former, a sharper peak could be seen with a smaller $E_{\mathrm{p}}-E_{\mathrm{p} / 2}$ of $0.028 \mathrm{~V}$, suggesting that fast electron transfer kinetics existed. Furthermore, the current response for the oxidation of UA was higher, which showed that the Co(II)TPP film could well catalyze the oxidation of UA.

Figure 3 shows the $\mathrm{CV}$ s of $\mathrm{AA}$ at different scan rates at the Co(II)TPP-GCE. The response current increased with the increase of the scan rate. A linear relationship $(r=0.994)$ could be found between the peak current and the square root of the scan rate in the range of 40 to $600 \mathrm{mV} \mathrm{s}^{-1}$ (inset). In addition, the Co(II)TPP-GCE used for the oxidation of AA did not show any current response after it was put into a pure supporting electrolyte, showing that the oxidation process of AA at Co(II)TPP-GCE was diffusion-controlled. A similar result could be obtained for UA (data not shown).

\section{Simultaneous determination of $A A$ and $U A$}

When AA and UA were present in the same sample, a broad anodic peak was observed at about $0.4 \mathrm{~V}$ at bare GCE (Fig. 4a). The peak potentials were indistinguishable. However, at the 


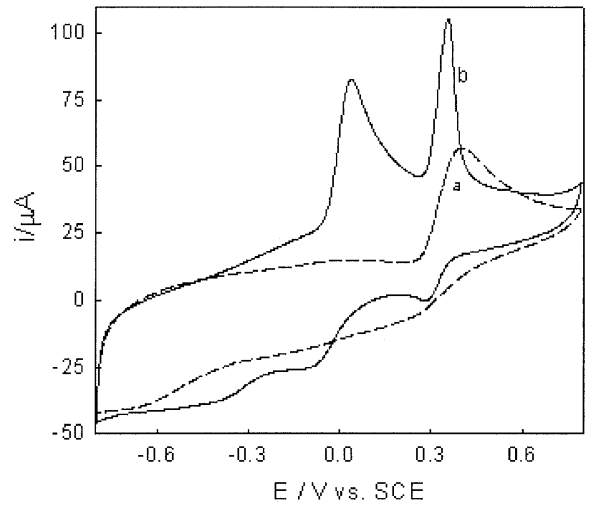

Fig. 4 Cyclic voltammograms for a mixture of $1 \mathrm{mM}$ UA and 3 $\mathrm{mM}$ AA in $0.1 \mathrm{M}$ PBS (pH 6.5) at a scan rate of $100 \mathrm{mV} \mathrm{s}^{-1}$. a, bare GCE; b, Co(II)TPP-GCE.

Co(II)TPP-GCE, the peaks were well separated. The anodic peaks appeared at about $0.32 \mathrm{~V}$ and $0.05 \mathrm{~V}$, respectively (Fig. $4 \mathrm{~b}$ ). The potential difference value was about $0.27 \mathrm{~V}$, which was large enough for the simultaneous determination of AA and UA in a coexistent solution. In addition, the response current for both were much larger, suggesting that the catalysis of Co(II)TPP would not be affected by the blending of analytes.

The investigation of mutual interferences is very important for the simultaneous determination of AA and UA. Figure 5 exhibits the linear scan voltammograms (LSVs) of UA under different concentrations, while the content of AA was kept constant. The peak current exhibited a linear relationship with UA in the range of $2.0 \times 10^{-6}-1.0 \times 10^{-4} \mathrm{M}(r=0.996)$. The detection limit was $5.0 \times 10^{-7} \mathrm{M}$. The calibration curve is shown in the insert. From the plot, it can be seen that an increase of UA concentration did not affect the response current of AA. The peak for AA could overlap though the content of UA changed. On the other hand, the relationship between peak current and AA concentration was studied, where the concentration of UA was fixed (data not shown). The trend was almost similar to the above discussed for the investigation of UA. Here, the peak current enhanced linearly with the increase of AA concentration. The linear range was $9.0 \times 10^{-6}-2 \times 10^{-3}$ $\mathrm{M}(r=0.996)$ with a detection limit of $5.0 \times 10^{-6} \mathrm{M}$. The peak height of the oxidation peak of UA remained almost unchanged, though AA concentration varied. Therefore, the variation of concentration for both analytes did not affect each other.

\section{Effect of $\mathrm{pH}$}

Figure 6A shows the effect of $\mathrm{pH}$ on the peak potential. Obviously, the oxidation peak potentials for UA and AA shift positively with the decrease of $\mathrm{pH}$. For UA, the slope of $E_{\mathrm{p}, \mathrm{a}} v s$. $\mathrm{pH}$ is about $66 \mathrm{mV} \mathrm{pH}^{-1}$, and $48 \mathrm{mV} \mathrm{pH}^{-1}$ for AA. The linear equations for them are $E_{\mathrm{p}, \mathrm{a}}=-0.066 \mathrm{pH}+0.7746(r=0.999)$ and $E_{\mathrm{p}, \mathrm{a}}=-0.048 \mathrm{pH}+0.3154(r=0.996)$, respectively. The potential difference value decreases with increasing $\mathrm{pH}$. For a positive shift of the peak potential for AA, the cause may be the following:

The oxidation mechanism of AA at the electrode is as follows: ${ }^{33}$

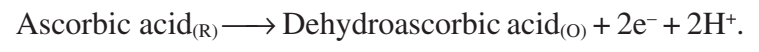

According to the Nernst equation, ${ }^{34}$

$$
E=E^{0}+\frac{0.0592}{2} \log \frac{c_{\mathrm{O}} c^{2} \mathrm{H}^{+} f_{\mathrm{O}} f_{\mathrm{H}^{+}}}{c_{\mathrm{R}} f_{\mathrm{R}}}
$$

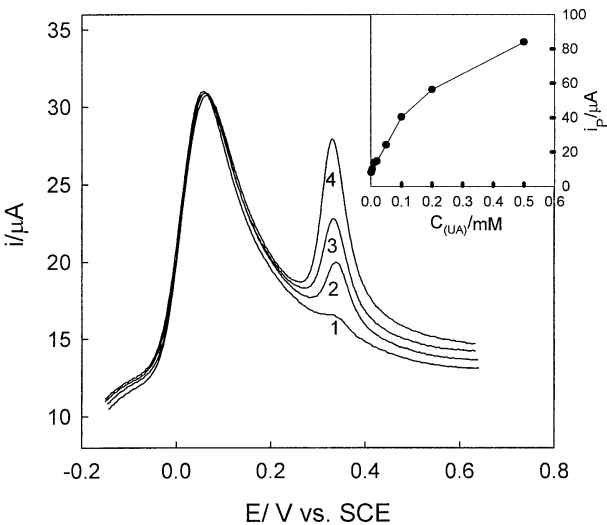

Fig. 5 Linear sweep voltammograms of UA and AA $(0.75 \mathrm{mM})$ at Co(II)TPP-GCE in $0.1 \mathrm{M}$ PBS (pH 6.5) at a scan rate of $100 \mathrm{mV} \mathrm{s}^{-1}$. The concentrations of UA from 1 to 4 correspond to $0.02,0.035,0.045$, and $0.063 \mathrm{mM}$, respectively. The inset shows the UA calibration plot.
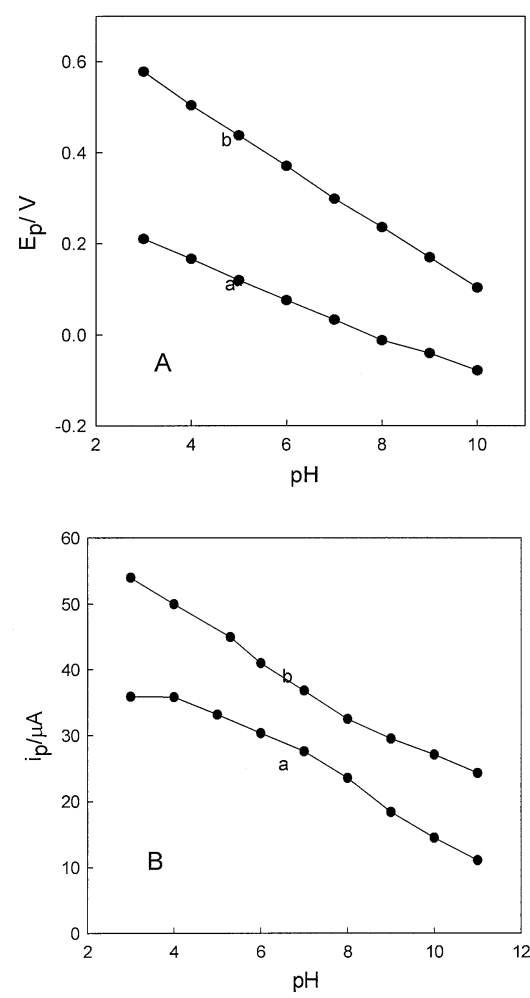

Fig. 6 The relationship between $\mathrm{pH}$ and peak potential (A) and the relationship between $\mathrm{pH}$ and peak current (B). a, $0.75 \mathrm{mM} \mathrm{AA}$; b, 0.1 mM UA.

where $c$ is the concentration, $f$ represents the activity coefficient, and $c_{\mathrm{O}}$ is correlation with $c_{\mathrm{R}}$. From Eq. (2), the following equation can be obtained:

$$
E=E^{0}-0.0592 \mathrm{pH}+\frac{0.0592}{2} \log \frac{k c_{\mathrm{R}} f_{\mathrm{O}} f_{\mathrm{H}^{+}}}{c_{\mathrm{R}} f_{\mathrm{R}}},
$$

where $k$ is assumed to be the correlation coefficient, and $f_{\mathrm{H}^{+}}$is affected by the ionic strength which is influenced by acidity. We then obtain 


$$
\begin{aligned}
& E=E^{0}-0.0592 \mathrm{pH}+\frac{0.0592}{2} \log f_{\mathrm{H}^{+}}+C, \\
& \Delta E=-0.0592 \Delta \mathrm{pH}+\frac{0.0592}{2} \log \frac{f_{1}}{f_{2}},
\end{aligned}
$$

where $C$ is a constant, $f_{1}$ and $f_{2}$ are activity coefficients of $\mathrm{H}^{+}$ under different $\mathrm{pH}$ values. From Eqs. (4) and (5), it can be seen that the peak potential shifts positively with the decrease of $\mathrm{pH}$. The $\Delta E$ value is not just $0.0592 \mathrm{~V}$ for the change of one $\mathrm{pH}$, which is the slope of the $E_{\mathrm{p}, \mathrm{a}} v s$. pH plot. It is influenced by $f_{\mathrm{H}^{+}}$. Here, the slope is about $48 \mathrm{mV}$ for $\mathrm{AA}$ in the $\mathrm{pH}$ range of 3 11. In addition, the electro-oxidation of UA also involves $2 \mathrm{e} / 2 \mathrm{H}^{+}$reaction. ${ }^{35}$ Therefore, a similar result can also be obtained. Here, the slope is about $66 \mathrm{mV}$ for UA.

Figure $6 \mathrm{~B}$ shows the variation of peak current with $\mathrm{pH}$ in 0.1 $\mathrm{M}$ PBS. From the plot, it can be seen that the oxidation peak current of AA and UA both increase with the fall of $\mathrm{pH}$ from 11 to 3 , indicating that proton has some responsibility for the increasing current. Here, the proton is the product of the oxidation reaction. The current should decrease with the increase of acidity. However, it is not the case. This phenomenon is probably due to the effect of acidity on the distribution of the various forms. For example, for $\mathrm{pH} 6.5$, the distribution ratios are $\mathrm{UA}=0.0076, \mathrm{UA}^{-}=0.096$, and $\mathrm{UA}^{2-}=$ $0.8963 .{ }^{24}$ The form of UA affected by $\mathrm{pH}$ is probably more favorable to electro-oxidation and a high response current. In

Table 1 Catalysis of different porphyrin modified electrodes

\begin{tabular}{|c|c|c|c|c|c|}
\hline \multirow{2}{*}{ Electrode $^{\mathrm{b}}$} & \multicolumn{2}{|c|}{$E_{\mathrm{p}, \mathrm{a}} v s . \mathrm{SCE} / \mathrm{V}$} & \multirow{2}{*}{$\begin{array}{c}\text { Separation/ } \\
\text { V }\end{array}$} & \multicolumn{2}{|c|}{$i_{\mathrm{p}, \mathrm{a}} / \mu \mathrm{A}$} \\
\hline & $\mathrm{UA}^{\mathrm{a}}$ & $\mathrm{AA}^{\mathrm{a}}$ & & UA & AA \\
\hline Co(II)TPP-GCE & 0.32 & 0.05 & 0.27 & 56.2 & 34.2 \\
\hline Cu(II)TPP-GCE & 0.32 & 0.17 & 0.15 & 38.1 & 21.7 \\
\hline Fe(III)TPPCl-GCE & 0.35 & 0.10 & 0.25 & 54.4 & 33.1 \\
\hline Mn(III)TPPCl-GCE & 0.35 & 0.09 & 0.26 & 58.7 & 36.4 \\
\hline $\mathrm{H}_{2} \mathrm{TPP}-\mathrm{GCE}$ & 0.32 & 0.11 & 0.21 & 44.5 & 29.4 \\
\hline
\end{tabular}
$(n=4)$

a. AA $(0.75 \mathrm{mM})$ and $\mathrm{UA}(0.2 \mathrm{mM})$ in $0.1 \mathrm{M}$ PBS (pH 6.5) unless otherwise noted.

b. Modified with $2 \mu \mathrm{l}$ of $4 \mathrm{mg} \mathrm{ml}^{-1}$ porphyrin. addition, the peak current obtained from AA increases slowly between $\mathrm{pH} 5.0-3.0$ and falls sharply when the $\mathrm{pH}$ is above 8 . When $\mathrm{pH}>12$, the response signal can not be found in $0.5 \mathrm{mM}$ AA solution. It is ascribed to the instability of AA in basic solution. Considering the physiological factors, such as the insatiability of AA in basic solution and low solubility of UA in acid solution, pH 6.5 was selected.

\section{The catalysis of different porphyrins modified electrode}

To understand the catalytic performance of different porphyrin modified electrodes, a comparison was made by analyzing AA and UA at GCE modified with $2 \mu \mathrm{lof} 4 \mathrm{mg} \mathrm{ml}^{-1}$ $\mathrm{Co}$ (II)TPP, $\mathrm{Cu}$ (II)TPP, $\mathrm{Fe}$ (III)TPPCl, $\mathrm{Mn}$ (III)TPPCl, $\mathrm{H}_{2}$ TPP, respectively. The results are given in Table 1. Although the response current of UA and AA at $\mathrm{Mn}$ (III)TPPCl-GCE was higher than that at $\mathrm{Co}(\mathrm{II}) \mathrm{TPP}-\mathrm{GCE}$, a better potential separation could be obtained at Co(II)TPP-GCE. Thus, Co(II)TPP was chosen here.

The electrooxidative mechanism of AA and UA at different electrodes has been extensively studied. ${ }^{22,36-39}$ The catalysis process of Co(II)TPP may be as follows:

$$
\begin{aligned}
& \mathrm{H}_{2} \mathrm{~A} \longrightarrow \mathrm{A}^{-}+2 \mathrm{H}^{+}+\mathrm{e}, \\
& \mathrm{Co}(\mathrm{II}) \mathrm{TPP}+\mathrm{A}^{-} \longrightarrow[\mathrm{ACo}(\mathrm{II}) \mathrm{TPP}]^{-}, \\
& {[\mathrm{ACo}(\mathrm{II}) \mathrm{TPP}]^{-} \longrightarrow \mathrm{Co}(\mathrm{I}) \mathrm{TPP}+\mathrm{A}_{\mathrm{ox}},} \\
& \mathrm{Co}(\mathrm{I}) \mathrm{TPP}-\mathrm{e} \longrightarrow \mathrm{Co}(\mathrm{II}) \mathrm{TPP} .
\end{aligned}
$$

Here, $\mathrm{H}_{2} \mathrm{~A}$ represents AA or UA. Among metalloporphyrins, Co(II)TPP has a better electrooxidative performance. This is ascribed to the fact that the CoTPP has a more positive reduction potential than others. ${ }^{40}$ It is then easier to activate and oxidize the UA or AA molecules.

\section{Stability and reproductively of Co(II)TPP-GCE}

Stability is an important consideration in the development of an electrochemical modified electrode. It was explored by

\begin{tabular}{|c|c|c|c|c|c|c|c|c|}
\hline \multirow{2}{*}{ Sample $^{\mathrm{a}}$} & \multicolumn{4}{|c|}{ AA } & \multicolumn{4}{|c|}{ UA } \\
\hline & Original/ $\mu \mathrm{M}$ & Added $/ \mu \mathrm{M}$ & Found/ $\mu \mathrm{M}$ & Recovery, \% & Original/ $\mu \mathrm{M}$ & Added/ $\mu \mathrm{M}$ & Found/ $\mu \mathrm{M}$ & Recovery, \% \\
\hline 1 & 14.4 & 50.0 & 62.3 & 96.7 & 137.9 & 100.0 & 228.3 & 96.0 \\
\hline 2 & - & 50.0 & 52.4 & 104.8 & 48.6 & 50.0 & 93.4 & 94.7 \\
\hline
\end{tabular}
monitoring the change of peak current. No apparent decrease of peak current was observed after 1 month of successive use. It was estimated that the usage life of the modified electrode was

\begin{tabular}{|c|c|c|c|c|c|c|}
\hline \multirow{2}{*}{ Electrode } & \multicolumn{4}{|c|}{ UA } & \multirow{2}{*}{$\begin{array}{l}\text { Usagelife/ } \\
\text { month }\end{array}$} & \multirow{2}{*}{$\begin{array}{c}\text { Potential } \\
\text { separation/V }\end{array}$} \\
\hline & Sensitivity $/ \mu \mathrm{A} \mu \mathrm{M}^{-1}$ & Linear range $/ \mu \mathrm{M}$ & Detection limit/ $\mu \mathrm{M}$ & $E_{\mathrm{p}, \mathrm{a}} / \mathrm{V}$ & & \\
\hline MBI-Au ${ }^{3}$ & 0.0152 & $1.0-300.0$ & 1.00 & 0.34 & 1 (day) & 0.26 \\
\hline MB-SGGCE ${ }^{24}$ & - & $0.001-50$ & 0.001 & 0.46 & 1 & 0.22 \\
\hline PDMA/GCE ${ }^{25}$ & 0.0276 & $1.25-68.75$ & 1.25 & 0.35 & - & 0.20 \\
\hline Co(II)TPP-GCE & 0.3703 & $2.0-100.0$ & 0.50 & 0.32 & 6 & 0.27 \\
\hline
\end{tabular}
at least 6 months. This was ascribed to the high stability and

Table 2 Recovery determination of AA and UA with Co(II)TPP-GCE $(n=6)$

a. Urine sample was diluted 20 times (No. 1) and 60 times (No. 2) by 0.1 M PBS (pH 6.5).

Table 3 Comparison of the performances of different modified electrodes 
strong hydrophobic property of Co(II)TPP. The sensor also displayed good reproducibility. In a series of 6 sensors, a relative standard deviation (RSD) of $5.1 \%$ was obtained by analyzing $0.01 \mathrm{mM} \mathrm{UA}$ in $0.1 \mathrm{M}$ PBS ( $\mathrm{pH}$ 6.5). The separation of the peak potential of AA and UA was about $0.27 \mathrm{~V}$ at all sensors.

\section{The recovery test of real sample}

The Co(II)TPP-GCE for the real sample determination was performed by measuring the concentration and the recovery of UA and AA in urine. The urine sample was filtrated and diluted with PBS ( $\mathrm{pH}$ 6.5) before measurements. The results are summarized in Table 2. Note that the recovery was a lightly lower than $100 \%$, which was probably due to the existence of interferents, ${ }^{23}$ such as purine, citrate and so on.

\section{Comparison with other modified electrode}

A comparison for the performances of the cobalt(II) tetrakisphenylporphyrin film modified electrode developed in this work with that developed in the literature ${ }^{3,24,25}$ is given in Table 3. Similar performances and advantages can be seen. The superiority of Co(II)TPP-GCE is mainly due to its simplicity, cheapness, high stability and long usage life.

\section{Conclusion}

This work has shown that metalloporphyrins can be used as catalyst for the oxidation of AA and UA. The Co(II)TPP-GCE shows good performances for the simultaneous determination of AA and UA. It separates the anodic peaks of AA and UA well. The difference value is about $0.27 \mathrm{~V}$. There is no interference for each other at $\mathrm{pH} 6.5$ in $0.1 \mathrm{M}$ PBS. Utilization of the sensor for the analysis of UA and AA in human urine was performed, and the results were satisfactory. Furthermore, porphyrin modified electrodes have various characteristics, such as simplicity, cheap, fastness, high stability, and excellent sensitivity for the determination of a mixture of AA and UA.

\section{Acknowledgements}

This project was supported by Hunan Provincial Natural Science Foundation of China (Grant No. 04JJ30047).

\section{References}

1. M. H. Alderman, Curr. Opin. Pharmacol., 2002, 2, 126.

2. J. S. Rodman, J. J. Williams, and C. M. Peterson, J. Urol., 1984, 131, 1039.

3. C. R. Raj and T. Ohsaka, J. Electroanal. Chem., 2003, 540, 69.

4. S. H. Huang, Y. C. Shih, C. Y. Wu, C. J. Yuan, Y. S. Yang, Y. K. Li, and T. K. Wu, Biosens. Bioelectron., 2004, 19, 1627.

5. D. M. Pérez, M. L. Ferrer, and C. R. Mateo, Anal. Biochem., 2003, 322, 238

6. K. Inoue, T. Namiki, Y. Iwasaki, Y. Yoshimura, and H. Nakazawa, J. Chromatogr., B, 2003, 785, 57.

7. S. Kasai, Y. Hirano, N. Motochi, H. Shiku, M. Nishizawa, and T. Matsue, Anal. Chim. Acta, 2002, 458, 263.

8. O. Arrigoni and M. Tullio, Biochim. Biophys. Acta, 2002, $1569,1$.

9. N. Q. Gan, R. X. Cai, and Z. X. Lin, Anal. Chim. Acta, 2002, 466, 257.

10. D. R. Shankaran, K. Iimura, and T. Kato, Sens. Actuators, $B, \mathbf{2 0 0 3}, 94,73$.

11. Y. J. Tang and M. J. Wu, Talanta, 2005, 65, 794.

12. S. L. Feng, J. Wang, X. G. Chen, and J. Fan, Spectrochim. Acta, Part A, 2005, 61, 841.

13. P. R. Tomás, M. L. Carmen, S. Antonio, and G. Ana, J. Pharm. Biomed. Anal., 2004, 34, 551.

14. A. Iwado, M. Mifune, H. Akizawa, N. Motohashi, and Y. Saito, J. Pharm. Biomed. Anal., 2003, 30, 1923.

15. N. Meissam and K. M. Mozhgan, Talanta, 2003, 6, 173.

16. S. F. Wang and D. Du, Sens. Actuators, B, 2004, 97, 373.

17. M. Arvand, S. Sohrabnezhad, M. F. Mousavi, M. Shamsipur, and M. A. Zanjanchi, Anal. Chim. Acta, 2003 491, 193.

18. X. Wu, Y. X. Diao, C. X. Sun, J. G. Yang, Y. B. Wang, and S. N. Sun, Talanta, 2003, 59, 95.

19. Y. J. Ma, M. Zhou, X. Y. Jin, B. Z. Zhang, H. Chen, and N. Y. Guo, Anal. Chim. Acta, 2002, 464, 289.

20. S. A. Wring and J. P. Hart, Analyst, 1992, 117, 1215.

21. A. Malinauskas, R. Garjonyt, R. Mažeikien, and I. Jureviciut, Talanta, 2004, 64, 121.

22. X. Lu, J. Jin, J. Kang, B. Lv, H. Liu, and Z. Geng, Mater. Chem. Phys., 2003, 77, 952.

23. L. Zhang and X. Q. Lin, Analyst, 2001, 26, 367.

24. S. B. Khoo and F. Chen, Anal. Chem., 2002, 74, 5734

25. P. R. Roy, T. Okajima, and T. Ohsaka, J. Electroanal. Chem., 2004, 561, 75 .

26. S. Amemiya, P. Bulhlmann, and Y. Umezawa, Anal. Chem., 1999, 71, 1049.

27. J. W. Long and R. W. Murray, Anal. Chem., 1998, 70, 3355

28. J. P. Lei, H. X. Ju, and O. Ikeda, J. Electroanal. Chem., 2004, 567, 331.

29. S. Nakagaki, F. L. Benedito, and F. Wypych, J. Mol. Catal. A: Chem., 2004, 1217, 121.

30. M. Patel and B. J. Day, Tre. Pharmcol. Sci., 1999, $20,359$.

31. A. D. Adler, F. R. Longo, and F. Kampas, J. Inorg. Nucl. Chem., 1970, 32, 2443.

32. H. Winnischofer, S. S. Lima, K. Araki, and H. E. Toma, Anal. Chim. Acta, 2003, 480, 97.

33. R. C. Matos, M. A. Augelli, C. L. Lago, and L. Angnes, Anal. Chim. Acta, 2000, 404, 151.

34. Z. X. Zhang, "Supermicro-electrode Electrochemistry (in Chinese)", 1998, Science Press, Beijing, 2.

35. J. L. Owens, H. A. Maesh, and J. G. Dryhurst, J. Electroanal. Chem., 1978, 105, 231.

36. C. Chen, S. H. Cheng, and Y. O. Su, J. Electroanal. Chem., 2000, 487, 51.

37. S. M. Chen and S. W. Chiu, Electrochim. Acta, 2000, 45, 4399.

38. I. F. Hu and T. Kuwama, Anal. Chem., 1986, 58, 3239

39. G. Dryhurst, J. Electrochem. Soc., 1971, 118, 699.

40. K. M. Kadish, G. Royal, E. V. Caemelbecke, and L. Guelettl, in "The Porphyrin Handbook, Metalloporphyrins in Nonaqueous Media: Database of Redox Potentials", ed. K. M. Kadish, 2000, 4, Academic Press, New York, 1 - 219. 